\title{
A steep road to climate stabilization
}

\section{Pierre Friedlingstein}

\section{The only way to stabilize Earth's climate is to stabilize the concentration of greenhouse gases in the atmosphere, but future changes in the carbon cycle might make this more difficult than has been thought.}

The present dependence on fossil fuels for energy means that as the demand for energy increases, so does the emission of greenhouse gases. The increasing concentration of these gases in the atmosphere has caused most of the warming observed worldwide over the twentieth century. Moreover, the global average surface temperature is projected to rise by as much as $6.4^{\circ} \mathrm{C}$ by the end of the twenty-first century if emissions are not curbed ${ }^{1}$. To avoid the potentially dangerous consequences of such climate changes, the concentration of greenhouse gases in the atmosphere must be stabilized at a level that is 'safe' for society and for the environment - a goal that will require a marked reduction in anthropogenic emissions.

Industrialized countries are currently focusing on 'climate mitigation' policies that, when implemented, will result in reduced emission of greenhouse gases. It was recently proposed that by 2020 each of these countries should reduce emissions to $60-75 \%$ of the amount that they emitted in 1990; and by 2050, to $25-50 \%$ of 1990 levels $^{2}$. However, no such agreement was reached at the last UN Framework Convention on Climate Change Conference of Parties, held in Bali in December 2007. Nevertheless, these proposals, if acted on soon, are good news. But, to paraphrase Neil Armstrong, that's one giant leap for policy-makers, but one small step for the global environment.

For a start, industrialized countries produce only about $50 \%$ of global greenhouse-gas emissions, and the proportion produced by industrializing countries such as China and India is growing. If it is assumed, optimistically, that industrializing countries will not increase their emission rates soon and if industrialized countries follow the above proposal, then global emissions in 2020 will be only 12-20\% less than in 1990.

From a glance at the global carbon cycle, it is clear that this reduction will not come close to stabilizing the concentration of greenhouse gases in the atmosphere. At present, deforestation and the combustion of fossil fuels release almost 10 billion tonnes of carbon into the atmosphere each year in the form of $\mathrm{CO}_{2}$ - the main greenhouse gas. Of this amount, about 4.5 billion tonnes accumulate in the atmosphere, and the rest is absorbed by the ocean and by land-based ecosystems ${ }^{1}$. To stabilize atmospheric $\mathrm{CO}_{2}$ at the current concentration, emissions would need to be reduced to the amount that is taken up by the ocean and land - about 5.5 billion tonnes, which equates to an immediate $45 \%$ reduction in global emissions of $\mathrm{CO}_{2}$. This roughly matches the objective proposed

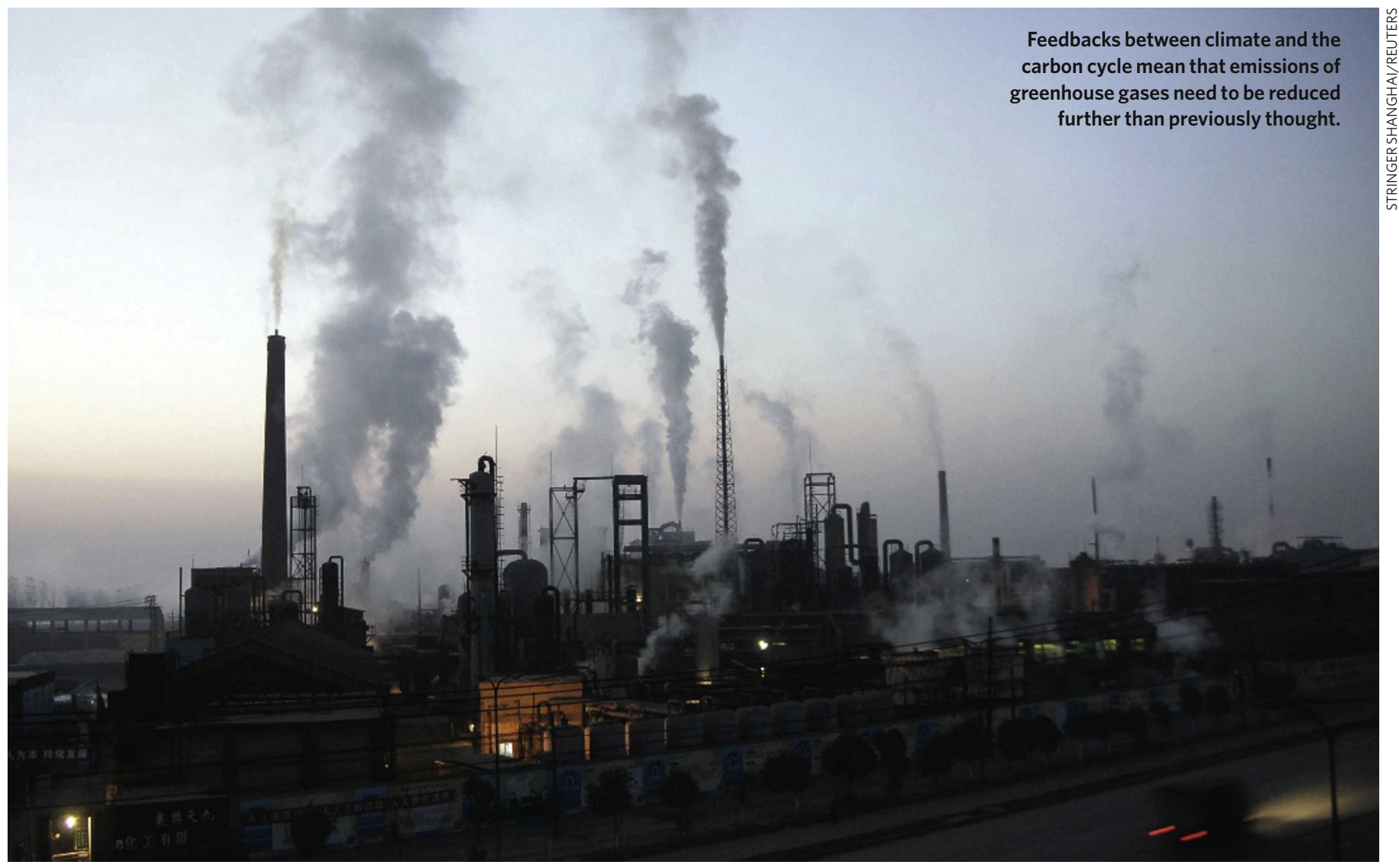




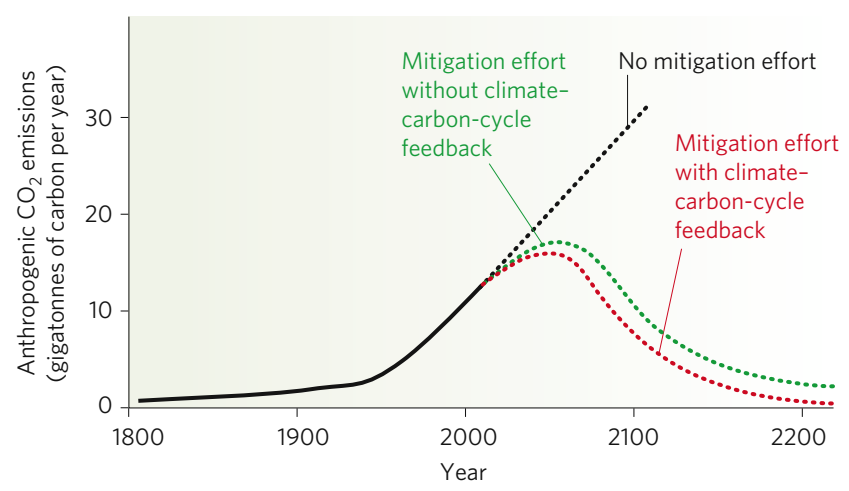

Figure 1 | Schematic illustration of past and projected trajectories of anthropogenic $\mathrm{CO}_{2}$ emissions. The amount of $\mathrm{CO}_{2}$ emitted from 1800 to the present is shown in black (solid line). Three projected trajectories of anthropogenic $\mathrm{CO}_{2}$ emissions are also shown (dashed lines): no effort to reduce emissions (black), and $\mathrm{CO}_{2}$ stabilization scenarios that do (red) or do not (green) take into account positive feedback between climate and the carbon cycle. It is clear that a greater reduction in emissions will be required to stabilize climate when feedback involving the carbon cycle is considered.

for the industrialized countries for 2050 , by which time considerably more $\mathrm{CO}_{2}$ will have accumulated in the atmosphere.

Moreover, such an immediate reduction would need to be reinforced over time, even if it were achieved. When the concentration of $\mathrm{CO}_{2}$ in the atmosphere increases, the concentration of the gas in the atmosphere is greater than the concentration in the upper ocean, creating a net flux of $\mathrm{CO}_{2}$ from the air to the ocean. But, if atmospheric $\mathrm{CO}_{2}$ concentrations stabilized, the average concentration in the ocean would slowly increase to match the concentration in the atmosphere, so uptake by the ocean would eventually cease. Thus, the immediate $45 \%$ reduction in global emissions would no longer be enough to keep $\mathrm{CO}_{2}$ concentrations constant.

In fact, climate stabilization might be even more complex. Recent observations and simulations indicate that the current uptake of atmospheric $\mathrm{CO}_{2}$ might be adversely affected by climate change. Careful measurements of the airborne proportion of anthropogenic emissions (that is, the proportion that remains in the atmosphere) show a small increasing trend in the past 50 years ${ }^{3}$. Therefore, the proportion of anthropogenic $\mathrm{CO}_{2}$ absorbed by the ocean and the land is becoming smaller. The Southern Ocean might be responsible for this reduction, because changes in ocean-surface winds seem to have decreased the amount of $\mathrm{CO}_{2}$ taken up by surface waters in this region in recent years.

Furthermore, simulations carried out with coupled climate and carbon-cycle models indicate that changes in climate will result in even greater reductions in the ability of land and the ocean to absorb anthropogenic $\mathrm{CO}_{2}$ by the end of the twenty-first century ${ }^{5}$. These simulations suggest that the combination of warming and drying will limit photosynthesis by plants and stimulate the decomposition of organic matter in soil, reducing the capacity of land-based ecosystems to store carbon (see page 289). In addition, it is widely thought that global warming will result in slower ocean circulation, leading to a decrease in the amount of carbon that is exported from the surface to the deep ocean and thereby reducing the flux of carbon from the air to the ocean. So it seems that future warming will reduce carbon sinks, leaving more $\mathrm{CO}_{2}$ in the atmosphere and leading, in turn, to greater warming.
This positive-feedback loop has implications for the pathway to stabilizing the concentrations of atmospheric greenhouse gases. If land-based and ocean ecosystems store less carbon than is expected in the future, then a greater effort will be needed, in terms of reducing anthropogenic emissions, to achieve a given concentration of atmospheric $\mathrm{CO}_{2}$. The potential importance of this effect is illustrated by simulations carried out for the Fourth Assessment Report of the Intergovernmental Panel on Climate Change (IPCC). These simulations indicate that to stabilize atmospheric $\mathrm{CO}_{2}$ concentrations at 450 parts per million (generally accepted as 'safe') by 2100 , cumulative emissions in the twenty-first century need to be reduced by a further $30 \%$ when this feedback is taken into account (Fig. 1).

Future policies aimed at stabilizing climate at a safe level will have to take many factors into consideration: the risks and associated financial costs of adapting to climate change; the risks of positive climate and carbon-cycle feedbacks reducing the efficiency of emission-reduction strategies; and the financial costs of reducing emissions. With the aim of informing such policies, the next assessment by the IPCC will explore various scenarios in which emissions are mitigated, including trajectories of emissions over time that result in stabilization of greenhouse-gas concentrations. These scenarios will be used by the climate research community to estimate the extent of future climate change, as well as its impact and the adaptations that might be required. This process differs fundamentally from past assessments by the IPCC, for which climate projections were based on non-mitigated emissions scenarios involving steady increases in greenhouse-gas concentrations over the twenty-first century.

This environmentally concerned view needs to be taken up and followed through by a succession of post-Kyoto regulations in the coming decades that lead to larger and larger reductions in greenhouse-gas emissions and eventually to stabilization of Earth's climate in a state that is safe for society and the environment. There is, unfortunately, no mystery: to stabilize climate, the concentration of greenhouse gases in the atmosphere must be stabilized, and to do so - given the limited capacity of the natural environment to absorb these gases - anthropogenic emissions will eventually need to be reduced to zero.

Pierre Friedlingstein is at the Institute Pierre Simon Laplace, Laboratory of Climate and Environment Sciences, CEA-Saclay, 91191 Gif-sur-Yvette, France.

1. Solomon, S. et al. (eds) Climate Change 2007: The Physical Science Basis. Contribution of Working Group I to the Fourth Assessment Report of the Intergovernmental Panel on Climate Change (Cambridge Univ. Press, Cambridge, UK, 2007).

2. The Vienna Climate Change Talks 2007, United Nations Framework Convention on Climate Change (http://unfccc.int/meetings/intersessional/awg_4_and_dialogue_4/ items/3999.php), and the United Nation Framework Convention on Climate Change, COP13, Bali, 2007 (http://unfccc.int/meetings/cop_13/items/4049.php)

3. Canadell, J. G. et al. Contributions to accelerating atmospheric $\mathrm{CO}_{2}$ growth from economic activity, carbon intensity, and efficiency of natural sinks. Proc. Natl Acad. Sci. USA 104, 18866-18870 (2007).

4. LeQuéré, C. et al. Saturation of the Southern Ocean $\mathrm{CO}_{2}$ sink due to recent climate change. Science 316, 1735-1738 (2007).

5. Friedlingstein, P. et al. Climate-carbon cycle feedback analysis: results from the C4MIP model intercomparison. J. Clim. 19, 3337-3353 (2006).

Acknowledgements | thank the Coupled Carbon Cycle Climate Model Intercomparison Project (C4MIP) community for fruitful discussions. The C4MIP project is supported by the International Geosphere Biosphere Program and the World Climate Research Program. This work was supported by the European Community funded project ENSEMBLES

Author Information Reprints and permissions information is available at npg.nature.com/reprints. Correspondence should be addressed to the author (pierre.friedlingstein@lsce.ipsl.fr). 